\title{
THE INTERCONNECTIVITY OF WEATHER SYSTEM AND OZONE CONCENTRATION OVER WEST AFRICA
}

\author{
M. L Akinyemi and C. C. Uhuegbu, \\ Department of Physics, Covenant University, \\ Ota, Ogun State Nigeria
}

\begin{abstract}
The relationship between some meteorological parameters and ozone distributions as revealed by satellite ЕРTOM over four West African stations namely, Lagos (Nigeria), Dakar (Senegal) Lamto (Ivory Coast) and Ekona (Cameroon) was studied for the period 1997 to 2002. The mean ozone concentration over these stations for the period were $270.8 \pm 0.3 D U$ at Lagos, $264.9 \pm 0.3 D U$ at Dakar, 269.8 $\pm 0.3 \mathrm{DU}$ and 269.0 $\pm 03 \mathrm{DU}$ at Lamto and Ekona respectively. The average monthly maximum ozone concentration of $288.6 \mathrm{DU}$ and $285.1 \mathrm{DU}$ respectively were observed for Lagos and Dakar, between July and August, which coincided with the period of tropical summer rainfall over the West African region. This coincidence could be attributed to reduction in the effect of the extra-tropical suction pump (ETSP) action responsible for the transportation of ozone concentration from the tropical stratosphere into the mid and high latitudinal region. This reduction may be due to decrease in the atmospheric heat engine expected to drive the ETSP, as the tropical surface temperature and evaporation are at their minimum during the raining season. The surface temperature and evaporation at Lagos-Nigeria both had significant negative correlation values of -0.73 and -0.68 with the ozone concentration respectively.
\end{abstract}

Keywords: West Africa, ozone variation, rainfall, temperature, evaporation

\section{INTRODUCTION}

Different amount of sunlight received at the surface of the earth (known as solar insolation) drive the weather and the observed winds on the earth. Likewise, temperature changes across earth's surface (i.e. in the horizontal) are directly linked to the speed and direction of the winds, both at the surface and at different heights. Changes in wind speed in the horizontal and in the vertical directions give rise to instabilities that create weather systems (Zerefos et al., 1997).
The primary source of variability in the lower atmosphere is transport processes. As a result of these processes, ozone in the lower stratosphere acts as a tracer of atmospheric motions. The motion of ozone is directly associated with the dynamics of motion in the atmosphere. This overall way of moving ozone around in the atmosphere is referred to as a transport process. It differs from photochemical processes that actually create and destroy ozone. Transport merely redistributes ozone from place to place (Holton, 1992; Cordero et al., 2003). Thus ob- 
servation of the redistribution of ozone in the atmosphere has some link in the weather pattern variation.

For instance, above a tropospheric highpressure system, rising air is brought into the stratospheric column at the tropopause and is removed from the column at higher altitudes. Since ozone-mixing ratio in the lower stratosphere increases with increasing altitude, the air brought into this column has less ozone than the air being removed. This results in decrease of ozone in the column. As this high-pressure system moves, it carries the low ozone column along with it. This explains why high-pressure systems are associated with decreased stratospheric ozone amounts. The effects of a lowpressure system are opposite; it results in increase in the ozone amounts (Charney and Drazin, 1961).

In the tropics the annual changes in temperature are fairly small, however at high latitudes, the tilt of Earth's axis results in significant variations in solar insolation as a result, annual changes in temperature are quite high. At the equator, the zonal wind varies minimally because of the minimum temperature gradient through the year. But at high latitudes, the zonal wind characters change rapidly through the course of the year due to the steeper temperature gradient that results in stronger zonal winds (Cordero et al., 2003; Morris et al., 2003).

\section{METHODOLOGY}

The data used in this study were obtained from satellite Earth Probe Total Ozone Mapping Spectrometer (EPTOMS) of NASA Goddard Institute for Space Study USA through the Internet service and Nigerian Meteorological Centre Oshodi. The interconnectivity of ozone concentration with meteorological parameters over four West African cities as revealed by satellite instrument EPTOMS were studied for the period from 1997 to 2002. The stations are Lagos in Nigeria, Dakar in Senegal, Lamto in Ivory Coast and Ekona in Cameroon

Lagos and Dakar are situated at latitude $6.6^{\circ} \mathrm{N}$, longitude $3.3^{\circ} \mathrm{E}$, and latitude $14.7^{0} \mathrm{~N}$, longitude $16.5^{\circ} \mathrm{W}$ respectively. Lagos is a city in southwest Nigeria, located on the Bight of Benin, an arm of the Atlantic Ocean, and is at an altitude of $10 \mathrm{~m}$ above sea level while Dakar is at an altitude of $35 \mathrm{~m}$. Dakar is in west Senegal, on the Cape Vert Peninsula and also on the Atlantic Ocean like Lagos. Lamto is in the Bandama Basin of Ivory Coast and Ekona is in Cameroon rainforest region, they are at latitude $6.22^{\circ} \mathrm{N}$, longitude $5.03^{\circ} \mathrm{W}$ and latitude $4.43^{\circ} \mathrm{N}$, longitude $9.33^{\circ} \mathrm{E}$ respectively, and altitude $76 \mathrm{~m}$ and $10 \mathrm{~m}$ above sea level respectively.

Lamto and Lagos are in the tropical long wet and short dry seasonal zone of West Africa, the tropical long wet season stretches from March to November, and the short dry season from December to February. Ekona is located in the rainforest region which is almost year round tropical wet zone. Dakar is the northernmost of the four stations and also in the westernmost point of the African continent. Unlike the other three stations it is in the border of hot and semiarid region with short raining season and long dry season. Figure 1 shows a sketch of West Africa and the four locations for this study.

\section{STATISTICAL ANALYSIS OF DATA}

The daily satellite measured total ozone concentration were retrieved from the archives of EPTOMS and used to analyse the day-to-day variation. Monthly and annual means of the ozone concentration over the four locations were calculated based on these daily values with an assumption that they represent the daily means. To study the long term trends, a linear regression analysis was used on the daily means. The variability was studied by using the standard deviation (S.D), the coefficient of relative variation (CRV), the annual coefficient of relative variation (ACRV), and the percent variability (PV) of ozone for each of the stations was calculated for the six years studied.

$$
\begin{gathered}
C R V=\frac{100 \times S . D}{\text { Mean }} \\
\text { AnnualCRV }=\frac{100 \times \text { AnnualS.D. }}{\text { AnnualMean }}
\end{gathered}
$$




$$
P V=\frac{100 \times \text { AnnualS.D. }}{\text { Maximum }}
$$

CRV is statistical parameter for comparing relative variability of two or more variants whose means are dissimilar.

Monthly meteorological data used for temperature, evaporation and rainfall were obtained from Nigeria Meteorological Centre Oshodi, Lagos, Nigeria.

\section{RESULTS AND DISCUSSIONS}

Transport and wind motion in the stratosphere are interconnected with that of the troposphere. This is important in order to balance both the chemical processes and radiative flux in both regions. The following results were obtained from this study. The mean ozone concentrations over the four stations for the period were $270.8 \pm 0.3 \mathrm{DU}$ at Lagos; 264.9 $\pm 0.3 \mathrm{DU}$ at Dakar; and $269.8 \pm 0.3 \mathrm{DU}$ and $269.0 \pm 03 \mathrm{DU}$ at Lamto and Ekona respectively. Ozone temporal oscillation period of between 2 and 6 days in the four stations was observed, while annual seasonal oscillation period of between 295 and 375 days were observed across the four stations (Akinyemi and Oladiran, 2007).
Day-to-day ozone variability is the difference in the daily mean ozone concentration and that of the previous day; it displays the level of frequency in daily ozone variability (Figure 2a). Also, the overall pattern of the day-to-day variation shows distinctly the intersequential changes in the seasonal ozone variability. The maximum increase in the day-to-day total ozone was $36.5 \mathrm{DU}$, while the maximum decrease was 37.7DU, yielding a maximum dayto-day variation of $\pm 37 \mathrm{DU}$ at Lagos. The standard deviation of the intersequential change was $13.2 \mathrm{DU}$, which correspond to a measure of the mean change from day to day. This observation of high frequency daily ozone variability was linked to the possible interconnectivity between convective activities and stratospheric ozone redistribution. And as well appreciated the presence of high convective activities could also be linked with change in stratospheric wind speed both in the horizontal and vertical direction. Changes in stratospheric ozone and winds affected the flow of energy at altitudes just below, this in turn affected the next lower altitudes, and all the way to the ground (Allen, 2004).

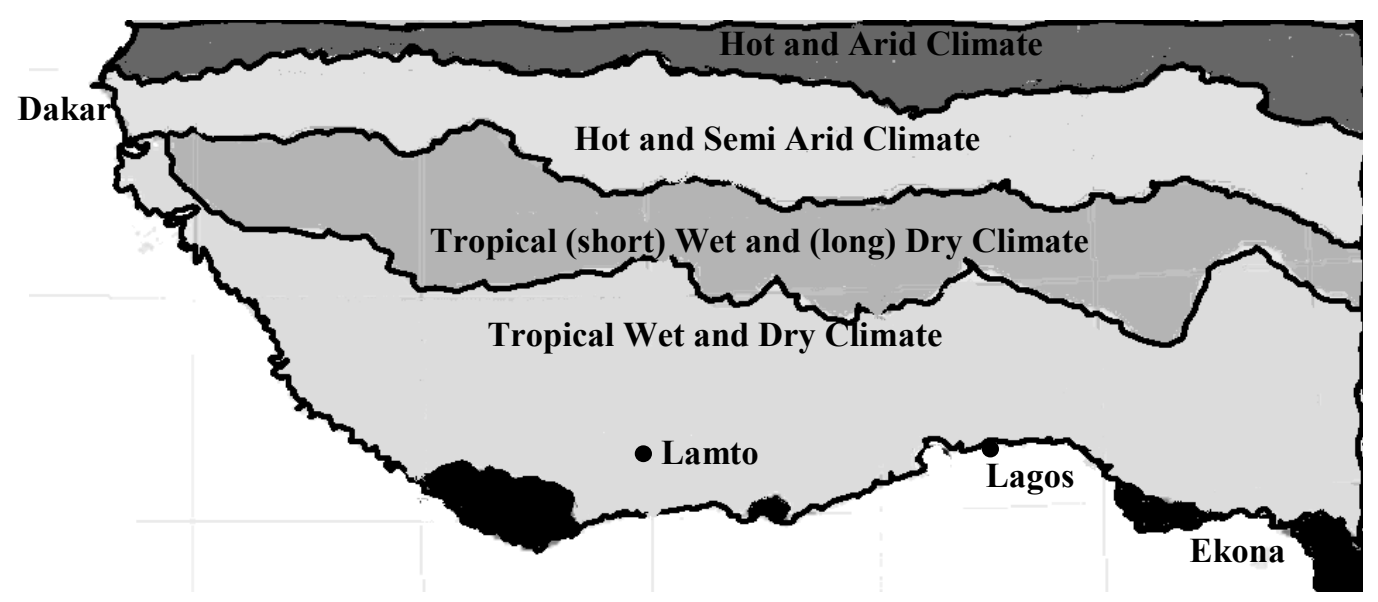

Tropical Wet Climate

Fig. 1: A sketch of the four locations in the West African Climatic Zones on which this study was based

Journal of Science and Technology @ KNUST December 2009 

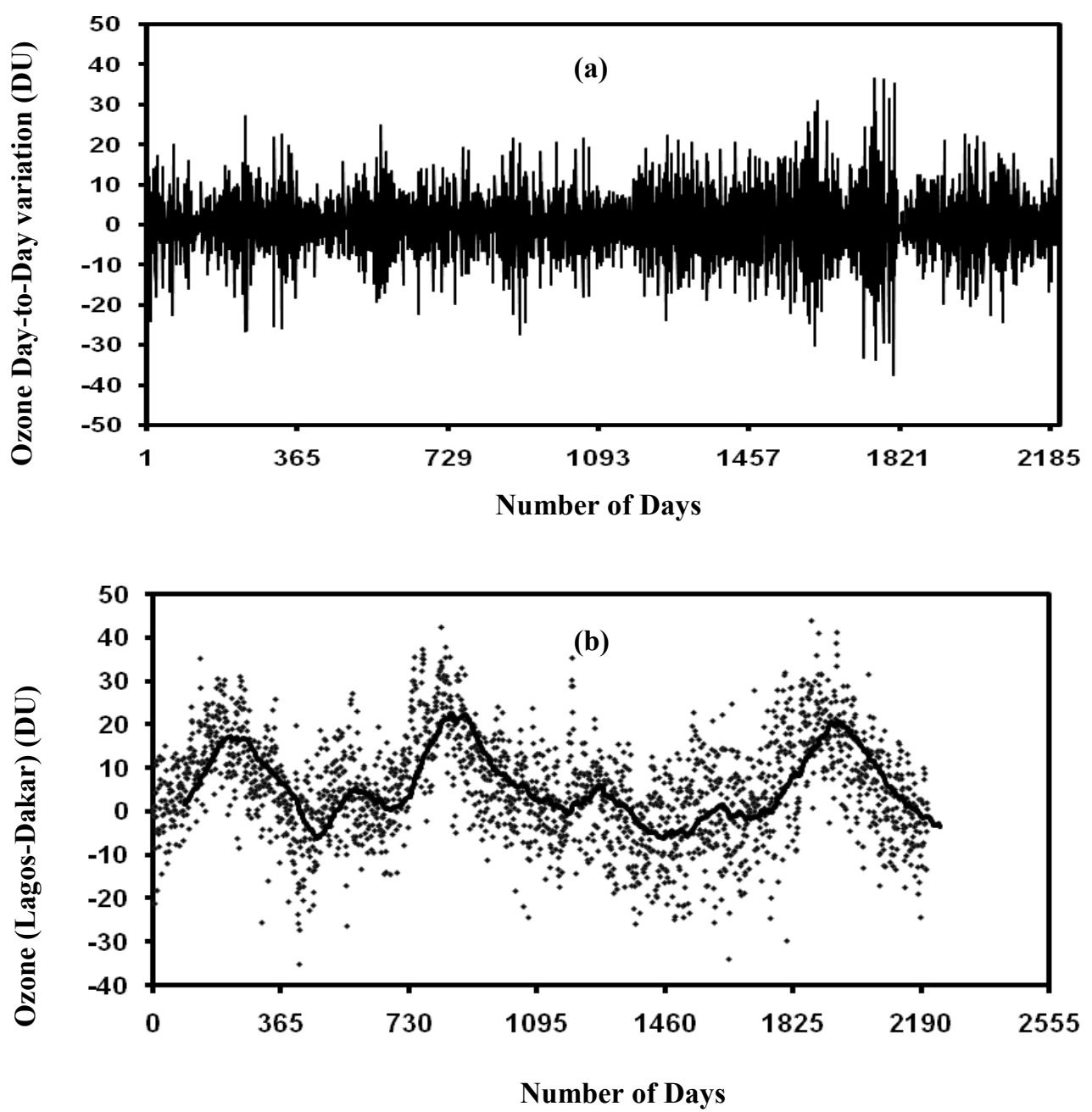

Fig. 2 (a and b): The day-to-day variation of ozone at Lagos; The difference between ozone concentration at Lagos and Dakar

It was also observed that mean ozone concentration at Dakar was for most part of the period studied lower than those of the other three stations (Figure 2b). The reason for this may be attributed to the fact that Dakar is the farthest and the westernmost point of the African continent thus looses more of its ozone rich air to the extratropical region through the continuous activities of the extra-tropical suction pump (ETSP).

Tropical summer rainfall over the West African region peaks between June and September. For the four West African stations studied, average monthly maximum ozone concentration of 288.6DU and 285.1DU respectively, was observed between July and August which coin- 
cided with the peak period of Tropical Summer rainfall over the West African region (Tables 1 and 2). Significant positive correlation with an average value of about +0.55 was observed between the rainfall pattern and total ozone variability at Lagos, Nigeria. The occurrence of maximum ozone concentration with the peak tropical summer rainfall could possibly be attributed to reduction in the strength of the ETSP action responsible for the transportation of ozone concentration from the tropical stratosphere into the mid and high latitudinal region. This reduction may be due to decrease in the energy from the atmospheric heat engine expected to drive the ETSP. The tropical rainfall season is characterized with minimum tropical surface temperature and evaporation at LagosNigeria, as they both had significant negative correlation values of -0.73 and -0.68 with the ozone concentration respectively. This might be linked with decrease in the atmospheric heat engine responsible for driving the ETSP. The ETSP is a phenomenon, whereby the extratropical stratosphere and mesosphere through relevant eddy effects act non-locally on the tropical stratosphere as a global scale fluiddynamical suction pump (Yulaeva et al., 1994; Rosenlof, 1995; Holton et al., 1995). Thus it may be inferred that there is interconnectivity between reduction in the strength of the ETSP and ozone distribution during the tropical rainfall season.

On the other hand an average monthly minimum ozone concentration of between 235.0DU and 250.3DU respectively were observed at Dakar, while the other three stations recorded a

Table 1: Statistical Analysis of ozone at Lagos, Nigeria (1997-2002)

\begin{tabular}{ccccccc}
\hline Year & Mean & Max & Month (Max) & Min & Month (Min) & \%Var \\
\hline 1997 & 269.0 & 289.7 & Jul & 247.6 & Dec & 14.5 \\
1999 & 277.7 & 293.2 & Aug & 259.3 & Jan & 11.6 \\
2000 & 270.4 & 286.7 & Aug & 246.1 & Dec & 14.2 \\
2001 & 267.3 & 283.3 & Jul & 244.9 & Feb & 13.6 \\
2002 & 273.0 & 292.1 & Aug & 250.8 & Dec & 14.1 \\
\hline
\end{tabular}

Mean = Annual mean of ozone concentration,

Max $=$ Maximum value

Month (Max) = Month of maximum ozone concentration,

Min = Minimum value,

Month (Min) = Month of minimum ozone concentration,

$\%$ Var (Variability) $=100 *$ Range / Maximum value,

Table 2: Statistical Analysis of ozone at Dakar, Senegal (1997-2002)

\begin{tabular}{ccccccc}
\hline Year & Mean & Max & Month (Max) & Min & Month (Min) & \% Var \\
\hline 1997 & 259.7 & 282.3 & Jul & 235.0 & Jan & 16.8 \\
1998 & 265.7 & 285.9 & Aug & 245.2 & Dec & 14.2 \\
1999 & 266.6 & 286.1 & Jul & 239.5 & Jan & 16.3 \\
2000 & 271.4 & 286.2 & Jul & 250.3 & Dec & 12.5 \\
2001 & 266.3 & 285.1 & Jul & 245.1 & Dec & 14.0 \\
2002 & 262.4 & 284.9 & Aug & 237.4 & Jan & 16.7 \\
\hline
\end{tabular}

Mean = Annual mean of ozone concentration

Max = Maximum value,

Month (Max) = Month of maximum ozone concentration,

Min = Minimum value,

Month $($ Min $)=$ Month of minimum ozone concentration,

$\%$ Var (Variability) $=100 *$ Range / Maximum value,

Journal of Science and Technology @ KNUST December 2009 

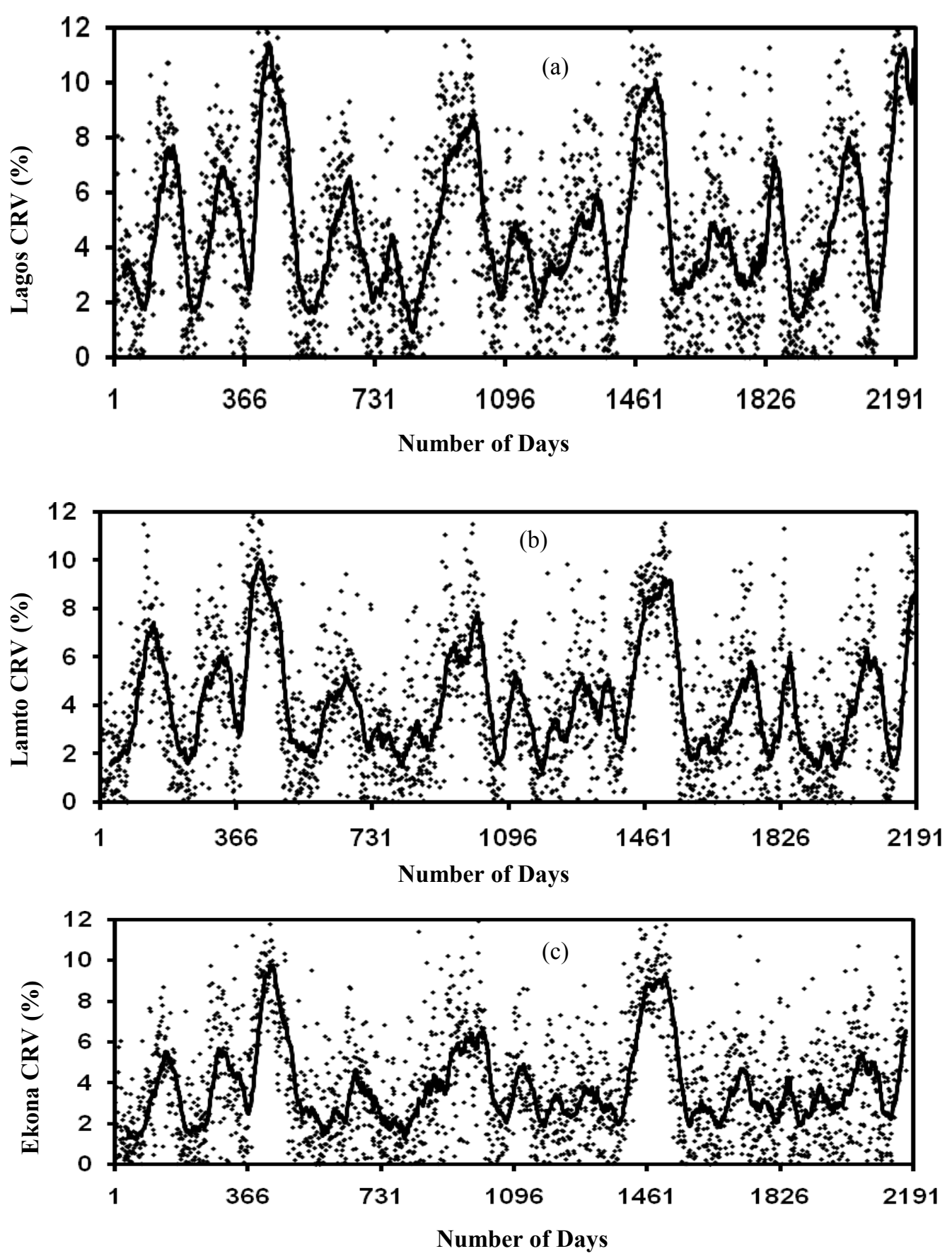

Fig. 3 (a-c): The QBO and Variability of ozone concentration at Lagos, Lamto and Ekona 
minimum between 240DU and 259.3DU. These were observed between December and January coinciding with the period of the dry season. The dry season over the West African region is characterized by high surface temperature and evaporation which then can be said to corroborate the earlier suggestion on the link between the strength of ETSP and ozone distribution. With high temperature and maximum evaporation during this period, the atmospheric engine that drives the ETSP may be suggested to be at its peak performance in the lifting of ozone rich air off the tropical stratosphere into the extratropical region.

Another strong connection observed was between the Quassi Biennial Oscillation (QBO) and the seasonal ozone concentration at Lagos, Lamto and Ekona. These three stations lie within the tropical long - wet seasonal region of West Africa. In the years of QBO occurrence annual mean ozone concentration at these three stations was about 10DU higher than that of Dakar which lies within the hotter semiarid region. In the years of non-QBO occurrence minimum disparities of about \pm 1 .4DU in ozone concentration was observed among the four stations. The QBO is the phenomenon in which tropical winds in the lower stratosphere switches from easterly to westerly and back to easterly within a space of two years (Dunkerton, 1997; WMO, 1998). Figure 3a-c showed the graphs of daily coefficient of relative variation at the three stations revealing the effect of the QBO on ozone concentration over the stations. The QBO is recognized as a major key factor in the year-to-year variation of temperature in the lower stratosphere. The QBO is confirmed to play a dominant role in the interannual variability of tropical lower stratospheric temperature, which in turn affects the lower altitude to some extent (Dunkerton, 1997).

\section{CONCLUSION}

Significant interconnectivities between ozone variability and the seasonal and temporal climatic condition over the four locations were evident. The high frequency day-to-day ozone variation at the four locations, amongst other factors was attributed to convective activities which could also be linked with variation in stratospheric wind speed. The effect of the atmospheric heat engine on the seasonal strength of ETSP was also suggested, as maximum lifting of ozone rich air from over the region to the extratropical zone coincided with the period of maximum temperature and evaporation at the West African region. This resulted in minimum ozone concentration during dry season.

A significant positive correlation between ozone concentration and rainfall pattern at Lagos was observed. The study also revealed some degree of interconnectivity between ozone variation and evaporation and temperature over the West African zone.

\section{REFERENCES}

Akinyemi, M. L. and Oladiran, E. O. (2007). Temporal and Spatial Variability of ozone Concentration over Four African Stations. J. Applied Sci., 7 (6): 913-917.

Allen, J. (2004). Ozone and Climate Change. NASA Earth Observatory Release, February, 2004.

Chandra, S. and McPeters, R.D. (1994). The solar cycle variation of ozone in the stratosphere inferred from Nimbus-7 and NOAA -11 satellites. J. Geophys. Res., 99: 2066520671.

Charney, J. and Drazin, P. (1961). Propagation of planetary scale disturbances from the lower into the upper atmosphere. J. Geophys. Res. 66: 83-109.

Cordero, E., Newman, P.A., Weaver, C. and Fleming, E. (2003). Stratospheric Dynamics and the Transport of Ozone and Other Trace Gases.http://hyperion.gsfc.nasa.gov/ code 916

Dunkerton, T.J. (1997). The Role of Gravity Waves in the Quasi-Biennial Oscillation. J.Geophy. Res., 102: 26053-26070. 
Holton, J. R (1992). An Introduction to Dynamic Meteorology. Academic Press, San Diego, pp. 511-554

Holton, J. R., Haynes, P. H., McyInty, M. E., Douglas, A. R., Rood, R. B. and Pfister, L. (1995). Stratosphere Troposphere Exchange. Review of Geophy. 33 (4): 403 439.

Kerr, J.B., Asbridge, I.A. and Evans, W.F.J. (1988). Intercomparison of Total Ozone Measured by the Brewer and Dobson Spectrophotometer at Toronto. J. Geophy. Res., 93: 11129-11140.

Morris, G., Barbara, G., Newman, P.A., Akin, A., Heaps, W., Crum, F., Larko, D. and Todaro, R. M. (2003) The Chemical, Thermal, and Dynamical Structure of Earth's Atmosphere http://hyperion.gsfc.nasa.gov/ code 916 . Accessed on 18/6/2004
Rosenlof, K.H. (1995). Seasonal Cycle of the Residual Mean Meridional Ciculation in the Stratosphere, J. Geophy. Res., 100: 5173-5191.

World Meteorological Organization (WMO) (1998). Scientific Assessment of Ozone Depletion, Global Ozone Research and Monitoring Project Report No. 44, Les Diablerets, Switzerland.

Yualeva, E., Holton, J.R. and Wallace, J.M. (1994). On the Cause of Annual Cycle in Tropical lower Stratospheric Temperature. J. Atmos. Sci., 51: 169-174.

Zerefos, C.S., Tourpali, K., Bojkov, B.R., Balis, D.S., Rognerund, B. and Isaksen, I.S.A. (1997). Solar activity total column ozone relationships: Observations and model studies with heterogeneous chemistry. J. Geophys. Res., 102: 1561-1569. 